\title{
Maternal educational level and the risk of persistent post-partum glucose metabolism disorders in women with gestational diabetes mellitus
}

\author{
Inês Gante ${ }^{1} \cdot$ Ana Carina Ferreira $^{2} \cdot$ Gonçalo Pestana $^{3} \cdot$ Daniela Pires $^{4,5} \cdot$ Njila Amaral $^{6} \cdot$ Jorge Dores $^{7}$. \\ Maria do Céu Almeida ${ }^{1}$. José Luis Sandoval ${ }^{8}$ (i)
}

Received: 20 August 2017 / Accepted: 11 December 2017 / Published online: 29 December 2017

c) Springer-Verlag Italia S.r.l., part of Springer Nature 2017

\begin{abstract}
Aims Gestational diabetes mellitus (GDM) occurs in 5-15\% of pregnancies, and lower maternal educational attainment has been associated with higher risk of GDM. We aimed to determine if maternal education level is associated with persistent post-partum glucose metabolism disorders in women with GDM.

Methods Retrospective cohort study of women with GDM followed in 25 Portuguese health institutions between 2008 and 2012. Educational attainment was categorised into four levels. Prevalence of post-partum glucose metabolism disorders (type 2 diabetes mellitus, increased fasting plasma glucose or impaired glucose tolerance) was compared and adjusted odds ratios calculated controlling for confounders using logistic regression.

Results We included 4490 women diagnosed with GDM. Educational level ranged as follows: $6.8 \%(n=307)$ were at level 1 ( $\leq$ 6th grade), $34.6 \%(n=1554)$ at level $2(6-9$ th grade), $30.4 \%(n=1364)$ at level $3(10-12$ th grade $)$ and $28.2 \%(n=1265)$ at level 4 ( $\geq$ university degree). At 6 weeks post-partum re-evaluation, $10.9 \%(n=491)$ had persistent glucose metabolism disorders. Educational levels 1 and 2 had a higher probability of persistent post-partum glucose metabolism disorders when compared to level $4(\mathrm{OR}=2.37$ [1.69;3.32], $p<0.001$ and $\mathrm{OR}=1.39[1.09 ; 1.76], p=0.008$, for level 1 and 2 , respectively), an association that persisted in multivariable logistic regression adjusting for confounders (level $1 \mathrm{OR}=2.25$ [1.53;3.33], $p<0.001$; level 2 OR $=1.43[1.09 ; 1.89], p=0.01$ ).

Conclusions Persistent post-partum glucose metabolism disorders are frequent in women with GDM and associated with lower maternal educational level. Interventions aimed at this risk group may contribute towards a decrease in prevalence of post-partum glucose metabolism disorders.
\end{abstract}

Keywords Diabetes $\cdot$ Gestational $\cdot$ Education $\cdot$ Women $\cdot$ Post-partum

Managed by Massimo Federici.

Electronic supplementary material The online version of this article (https://doi.org/10.1007/s00592-017-1090-y) contains supplementary material, which is available to authorized users.

Inês Gante

inesrcgante@gmail.com

José Luis Sandoval

jose.sandoval@cantab.net

Extended author information available on the last page of the article

\section{Introduction}

Gestational diabetes mellitus (GDM), defined as decreased glucose tolerance diagnosed during pregnancy, is estimated to occur in $5-15 \%$ of pregnancies $[1,2]$. Insulin resistance, caused partly by placental hormones and maternal adiposity, is recognised as the most important aetiological factor [3].

GDM was associated with adverse foetal, labour and maternal outcomes [2, 4-6]. As for maternal complications, a higher rate of hypertensive disorders (gestational hypertension, preeclampsia and eclampsia) [7] and increased risk of developing glucose metabolism disorders after pregnancy such as type 2 diabetes mellitus (type 2 DM), impaired fasting glucose or impaired glucose tolerance have been described [8]. GDM increases the risk of developing type 
2 DM up to seven times. Therefore, screening for type 2 DM and other glucose metabolism disorders at 6-12 weeks after delivery is mandatory according to current guidelines [9]. Moreover, studies have shown that all types of glucose metabolism disorders are associated with increased risk of cardiovascular disease, which is higher in participants meeting the criteria for type $2 \mathrm{DM}[10,11]$.

Identified risk factors for GDM include Asian and black ethnicity, increased maternal age, obesity, polycystic ovary syndrome, personal history of GDM and family history of diabetes [2]. Known predictive factors for persisting glucose metabolism disorders after pregnancy are obesity, GDM diagnosed before the 24th week of gestation and requirement of insulin treatment to achieve glycemic control during pregnancy $[8,12]$.

Maternal education is an additional risk factor for glucose metabolism disorders in the general population [13] as well as for GDM, as recently shown by Bouthoorn et al. [14]. However, its role as a predictive factor for persistence of glucose metabolism disorders after a pregnancy with a GDM diagnosis has not, to the best of our knowledge, been explored.

The aim of this study was to determine if maternal educational level was associated with increased risk of persisting post-partum glucose metabolism disorders in women with GDM.

\section{Methods}

We performed a retrospective cohort study of pregnant women diagnosed with GDM, who delivered in Portugal between 2008 and 2012 .

\section{Study population}

Data were obtained from the Portuguese National Registry of GDM with permission from the database coordinatorthe Study Group of the Portuguese Society of Diabetology (SGPSD).

GDM diagnosis was established using the criteria recommended by the Portuguese Directorate-General of Health (PDGH). Until February 2011, diagnosis was based on the Carpenter and Coustan's criteria, with a 100-g 3-h oral glucose tolerance test (OGTT), after a selective screening strategy in the 1st trimester and between 24 and 28 gestational weeks [15]. After February 2011, diagnosis was established using a universal screening strategy based on the International Association of Diabetes and Pregnancy Study Groups' criteria, American Diabetes Association (ADA) and the World Health Organisation-fasting plasma glucose in the 1st trimester and 75-g 2-h OGTT between 24 and 28 gestational weeks [1, 16, 17]. To determine if different diagnostic criteria could be an effect modifier of the relationship between maternal education and the outcome, an interaction term between maternal education and diagnostic criteria was added to the logistic regression analysis (see below). This was not significant $(p=0.33)$, and, consequently, we present our results without stratification by this variable.

Women with history of diabetes and those with twin pregnancies were not included in the database.

Data were collected from clinical records of women with GDM followed in 25 Portuguese public sector health institutions, from a total of 44 institutions invited to participate in the study and comprising all Portuguese continental districts. Datasets were aggregated and validated by the SGPSD, according to the data provided by the PDGH. Data were blinded with respect to patient and health institution's identification, ensuring anonymity of the collected data. This study complies with the Declaration of Helsinki on medical protocol and ethics. Each participating hospital's institutional review board approved data collection. Given the retrospective nature of this study and the use of anonymised data, participants' written consent was not required.

\section{Outcome variable}

The primary outcome was defined by the presence or absence of any glucose metabolism disorder at 6 weeks postpartum [9], defined as a composite of either type 2 DM or increased fasting plasma glucose or impaired glucose tolerance in a 2-h 75-g OGTT. Type $2 \mathrm{DM}$ was diagnosed in the presence of a plasma glucose $\geq 7 \mathrm{mmol} / \mathrm{L}$ after a $8 \mathrm{~h}$ fast or a $2 \mathrm{~h}$ plasma glucose $\geq 11 \mathrm{mmol} / \mathrm{L}$ during an OGTT; increased fasting plasma glucose as fasting plasma glucose of 5.5-6.9 $\mathrm{mmol} / \mathrm{L}$ and impaired glucose tolerance as plasma glucose $7.7-10.9 \mathrm{mmol} / \mathrm{L} 2 \mathrm{~h}$ after an OGTT $[9,12,15]$. No differences in how the outcome was measured were expected to have occurred between the groups defined by maternal educational level.

\section{Covariates}

The predictor variable, maternal educational level, was divided into four categories: level 1 (6th grade or less), level 2 (from 6th to 9th grade), level 3 (from 10th to 12th grade) and level 4 (university degree or higher).

Potential confounders were included as covariates in the statistical analysis. These include demographic (maternal age and district) and biometric characteristics (pre-pregnancy body mass index (BMI)—categorised into normal $<25 \mathrm{~kg} / \mathrm{m}^{2}$, overweight $\geq 25$ and $<30 \mathrm{~kg} /$ $\mathrm{m}^{2}$ and obese $\geq 30 \mathrm{~kg} / \mathrm{m}^{2}$; and gestational weight gainclassified as a weight increase below, within or above the limits established by the 2009 Institute of Medicine 
recommendations [18]) and obstetric history (nulliparous, previous pregnancy with or without GDM).

Women received education on diet, exercise and appropriate glycemic targets. According to the guidelines of the Portuguese General-Directorate of Health [19], the goal of therapy was to reduce fasting glucose to $3.3-5.0 \mathrm{mmol} / \mathrm{L}$ and the $1 \mathrm{~h}$ postprandial level to $5.5-6.6 \mathrm{mmol} / \mathrm{L}$ in more than $90 \%$ of the glucose measurements. Insulin was started if the glycemic targets were not achieved within 1-2 weeks with non-pharmacological therapy. Gestational age at GDM diagnosis (determined using obstetric ultrasound), the delay between diagnosis and first GDM obstetric appointment and the need of insulin therapy were also included in the analysis.

The mean value of $\mathrm{HbA} 1 \mathrm{c}$ in the third trimester was obtained, but not included in the multivariable model, as it would not be a predictor but a consequence of glucose metabolism disorders.

\section{Statistical analysis}

Continuous variables are presented as mean \pm standard deviation (SD) and categorical variables as number and frequency.

In order to identify an association between educational level and the persistence of glucose metabolism disorders after delivery, we performed a univariable logistic regression analysis with glucose metabolism disorders as the outcome and educational level as a predictor. Multivariable logistic regression analysis was used to adjust for confounding variables (age, district, pre-pregnancy BMI, gestational weight gain, obstetric history, week of diagnosis, delay to specialist appointment and insulin-requiring GDM).

To assess if an effect modification of educational level on the outcome could be observed for maternal age, year of diagnosis, geographical location or number of previous deliveries (using only multiparous women), we performed a logistic regression including interaction terms for each of the variables individually. For this analysis, educational level was dichotomised into two groups: levels 1-2 and $3-4$. Due to chance alone, we would expect 0.20 of the four interaction tests to be statistically significant at the $p<0.05$ level.

The need for insulin therapy during pregnancy was used as a surrogate for lack of glycemic control. We performed logistic regression using this variable as an outcome and educational level and the previously mentioned confounders as predictors.

All data were analysed using STATA 13.1 and R 3.2.2. A two-sided $p<0.05$ was considered significant and $95 \%$ confidence intervals are presented.

\section{Missing data}

Missing data for the explanatory variable (educational level) were assumed to be missing completely at random, and participants with missing data for this variable were excluded from the analysis. We assumed missing values for the outcome (persistent post-partum glucose metabolism disorders) were missing at random (MAR). By MAR we mean that the missingness of the outcome may be determined by other variables, such as education, with previous studies having reported that more educated women have a higher probability of returning for the re-evaluation appointment 6 weeks after delivery than least educated ones [20-22]. To address this limitation, multiple imputation was performed for the outcome variable. We used the mi package of STATA to create 40 imputed datasets using chained equations which were then combined and analysed. All potential confounders used in the multivariable logistic models were included in the imputation model. Results from imputed data did not differ from the ones obtained by complete case analysis, what is consistent with previous reports on outcome imputation [23]. As such, complete case analysis (only including participants with data for the outcome) was reported. The descriptives of participants with missing data can be found in Table S1, and we could observe that those with missing data for maternal education did not considerably differ from those included in the complete case analysis.

\section{Results}

The cohort used in this study comprises 4490 women diagnosed with gestational diabetes mellitus. The original dataset was composed of 8266 women. Women with missing data for the outcome $(n=2944)$ and/or the predictor $(n=1636)$ were excluded from the analysis $(n=3776)$.

Mean age \pm SD of participants was $33.2 \pm 5.1$ years. While 44.2\% $(n=1923)$ had a normal pre-pregnancy BMI, $30.5 \%(n=1329)$ were overweight, and $25.3 \%(n=1100)$ were obese. Concerning educational level, $6.8 \%(n=307)$ of the participants belonged to level $1,34.6 \%(n=1554)$ to level 2, 30.4\% $(n=1364)$ to level 3 and $28.2 \%(n=1265)$ to level 4. Baseline characteristics of the participants stratified by educational level are shown in Table 1 .

The mean \pm SD for the week of GDM diagnosis was $26.0 \pm 7.9$ and $2.8 \pm 3.5$ weeks for the delay between diagnosis and first GDM obstetric appointment.

A total of $11.9 \%(n=532)$ of the women had a previous pregnancy with a diagnosis of GDM, $41.1 \%(n=1835)$ had a pregnancy without this diagnosis, and $46.9 \%(n=2093)$ were nulliparous. The mean $\pm \mathrm{SD}$ for third trimester $\mathrm{HbA1c}$ measurement was $5.3 \pm 0.5 \%(34 \pm 6 \mathrm{mmol} / \mathrm{mol})$. Twentyseven per cent $(n=1142)$ experienced an excessive weight 
Table 1 Baseline characteristics of participants, overall and according to their educational level

\begin{tabular}{|c|c|c|c|c|c|}
\hline & \multirow[t]{2}{*}{ Full cohort $(n=4490)$} & \multicolumn{4}{|c|}{ Educational level $(\mathrm{NA}=0)$} \\
\hline & & $\begin{array}{l}\text { Level } 1(6.8 \%, \\
n=307)\end{array}$ & $\begin{array}{l}\text { Level } 2(34.6 \% \\
n=1554)\end{array}$ & $\begin{array}{l}\text { Level } 3(30.4 \%, \\
n=1364)\end{array}$ & $\begin{array}{l}\text { Level } 4(28.2 \%, \\
n=1265)\end{array}$ \\
\hline Age $(\mathrm{NA}=6)$, years & $33.2 \pm 5.1$ & $36.1 \pm 4.7$ & $32.9 \pm 5.5$ & $32.1 \pm 5.1$ & $33.8 \pm 4.2$ \\
\hline \multicolumn{6}{|c|}{ Pre-pregnancy BMI $(\mathrm{NA}=138), \%(n)$} \\
\hline Normal & $44.2(1923)$ & $30.6(90)$ & $36.7(552)$ & $46.4(615)$ & $54.2(666)$ \\
\hline Overweight & $30.5(1329)$ & $34(100)$ & $32.1(482)$ & $29.1(385)$ & $29.5(362)$ \\
\hline Obese & $25.3(1100)$ & $35.4(104)$ & $31.3(470)$ & $24.5(325)$ & $16.4(201)$ \\
\hline $\begin{array}{l}\text { Week of diagnosis } \\
\quad(\mathrm{NA}=61)\end{array}$ & $26 \pm 7.9$ & $25.8 \pm 7.3$ & $25.7 \pm 8.1$ & $26.2 \pm 7.9$ & $26.3 \pm 8.0$ \\
\hline $\begin{array}{c}\text { Delay between GDM } \\
\mathrm{dx} \text { and appointment } \\
(\mathrm{NA}=214), \text { days }\end{array}$ & $2.8 \pm 3.5$ & $2.5 \pm 2.7$ & $3.1 \pm 3.9$ & $2.8 \pm 3.5$ & $2.5 \pm 3.2$ \\
\hline $\begin{array}{l}\text { Insulin-requiring GDM } \\
(\mathrm{NA}=0), \%(\mathrm{n})\end{array}$ & $34.8(1561)$ & $41(126)$ & $39.2(609)$ & $32.5(443)$ & $30.3(383)$ \\
\hline $\begin{array}{l}\text { 3rd Trimester HbA1c } \\
\quad(\mathrm{NA}=1264), \% \\
(\mathrm{mmol} / \mathrm{mol})\end{array}$ & $5.3 \pm 0.5(34 \pm 6)$ & $5.4 \pm 0.6(36 \pm 7)$ & $5.3 \pm 0.5(34 \pm 6)$ & $5.3 \pm 0.5(34 \pm 6)$ & $5.3 \pm 0.6(34 \pm 7)$ \\
\hline \multicolumn{6}{|c|}{ Previous pregnancy $(\mathrm{NA}=30), \%(n)$} \\
\hline Nulliparous & $46.9(2093)$ & $23.3(71)$ & $34.5(531)$ & $52.8(717)$ & $61.6(774)$ \\
\hline No previous GDM & $41.1(1835)$ & $67.2(205)$ & $52.6(811)$ & $35.5(482)$ & $26.8(337)$ \\
\hline Previous GDM & $11.9(532)$ & $9.5(29)$ & 12.9 (199) & $11.6(158)$ & $11.6(146)$ \\
\hline \multicolumn{6}{|c|}{ Weight gain during pregnancy $(\mathrm{NA}=255), \%(n)$} \\
\hline Normal & $40.1(1698)$ & $37.3(106)$ & $39.6(583)$ & $40.9(527)$ & $40.5(482)$ \\
\hline Excessive & $27(1142)$ & $29.6(84)$ & $27.9(411)$ & $29(374)$ & $22.9(273)$ \\
\hline Reduced & $32.9(1395)$ & $33.1(94)$ & $32.5(479)$ & $30.1(387)$ & $36.6(435)$ \\
\hline \multicolumn{6}{|l|}{ Diagnostic criteria, \% $(n)$} \\
\hline $\begin{array}{l}\text { Carpenter and } \\
\text { Coustan }\end{array}$ & $63.2(2837)$ & $69.4(213)$ & $63.6(989)$ & $62.2(848)$ & $62.2(787)$ \\
\hline $\mathrm{ADA} / \mathrm{WHO}$ & $36.8(1653)$ & $30.6(94)$ & $36.4(565)$ & $37.8(516)$ & $37.8(478)$ \\
\hline $\begin{array}{l}\text { Gluc Metab disorder } \\
(\mathrm{NA}=0), \%(n)\end{array}$ & $10.9(491)$ & $19.9(61)$ & $12.7(197)$ & $8.3(113)$ & $9.5(120)$ \\
\hline $\begin{array}{l}\text { Impaired fasting } \\
\text { glucose }\end{array}$ & $1.4(61)$ & $1.6(5)$ & $1.7(27)$ & $1.2(16)$ & $1.0(13)$ \\
\hline $\begin{array}{l}\text { Impaired glucose } \\
\text { tolerance }\end{array}$ & $8(357)$ & $16.3(50)$ & $8.9(139)$ & $5.9(81)$ & $6.9(87)$ \\
\hline Diabetes & $1.6(73)$ & $2.0(6)$ & $2.0(31)$ & $1.2(16)$ & $1.6(20)$ \\
\hline
\end{tabular}

NA indicates missing data. Data are mean $\pm \mathrm{SD}$, unless otherwise specified

gain according to the IOM guidelines and $34.8 \%(n=1561)$ needed insulin therapy during pregnancy.

At the 6 weeks post-partum re-evaluation, $10.9 \%$ ( $n=491)$ were diagnosed with persistent glucose metabolism disorders. Impaired glucose tolerance was the most prevalent type of glucose metabolism disorder, occurring in $8.0 \%(n=357)$. Post-partum diabetes and impaired fasting glucose were present in $1.6 \%(n=73)$ and $1.4 \%(n=61)$, respectively.

When stratified by educational level, significant differences were observed between groups. Notably, less educated women were older $(36.1 \pm 4.7$ level 1 vs. $33.8 \pm 4.2$ level 4), had a higher pre-pregnancy BMI (30.6\% level 1 vs. $54.2 \%$ level 4, had normal pre-pregnancy BMI), were more frequently multiparous $(23.3 \%$ were nulliparous in level 1 vs. $61.6 \%$ in level 4) and had a higher percentage of excessive weight gain during pregnancy $(29.6 \%$ level 1 vs. $22.9 \%$ level 4 ). Moreover, less educated women had a higher percentage of post-partum glucose metabolism disorders (19.9\% level 1 vs. 9.5\% level 4 ) and higher need of insulin to achieve glycemic control during pregnancy ( $41.0 \%$ level 1 vs. $30.3 \%$ level 4). The remaining baseline clinical, laboratory and demographic data, as well as missing data details, can be found summarised in Table 1 and Table S2. 


\section{Lower educational level correlates with a higher probability of persistent post-partum glucose metabolism disorders}

We performed a univariable analysis (Fig. 1a) to correlate educational levels (as well as other predictors, namely age, pre-pregnancy BMI, week of diagnosis, delay between diagnosis and specialist appointment, weight gain, insulinrequiring GDM and previous pregnancy information) with post-partum glucose metabolism disorders. Educational levels 1 and 2 had a statistically significant higher probability of having persistent post-partum glucose metabolism disorders when compared to level $4(\mathrm{OR}=2.37$ [1.69;3.32], $p<0.001$ and $\mathrm{OR}=1.39$ [1.09;1.76], $p=0.008$, for level 1 and 2, respectively). Noticeably, insulin-requiring participants or those with a previous diagnosis of GDM also had a significantly higher probability of persistent post-partum glucose metabolism disorders in this univariable analysis $(\mathrm{OR}=2.36$ $[1.95 ; 2.85], p<0.001$ and $\mathrm{OR}=1.57[1.19 ; 2.06], p=0.001$, respectively).

After adjustment for the previously described confounders using multivariable logistic regression (Fig. 1b), lower educational levels 1 and 2 were associated with a significantly higher probability of persistent post-partum glucose metabolism disorders (level 1 OR $=2.25[1.53 ; 3.33]$, $p<0.001$; level 2 OR $=1.43$ [1.09;1.89], $p=0.01)$. In addition, participants requiring insulin to achieve glycemic control were also associated with this outcome $(\mathrm{OR}=1.88$ [1.50;2.34], $p<0.001)$. Significance could also be observed for age (OR $=1.03[1.01 ; 1.05], p=0.007)$, week of diagnosis $(\mathrm{OR}=0.97$ [0.96;0.99], $p<0.001)$ and overweight participants $(\mathrm{OR}=1.35[1.05 ; 1.75], p=0.02)$. Previous pregnancy with GDM was not predictive of the outcome when compared to nulliparous women $(\mathrm{OR}=1.17[0.87 ; 1.58]$, $p=0.31$ ). However, having a pregnancy without previous diagnosis of GDM was related to a lower probability of persistent post-partum glucose metabolism disorders $(\mathrm{OR}=0.62[0.49 ; 0.80], p<0.001)$.

\section{Maternal age modifies the effect of educational level on persistent post-partum glucose metabolism disorders}

While no effect modification could be observed by district of origin, year of diagnosis or number of previous deliveries (in multiparous women) (Fig. S2a, Fig. S2b and Table S3), a significant interaction was detected for maternal age (coefficient $=-0.04[-0.08 ;-0.01], p=0.02)$. The probability of (a)

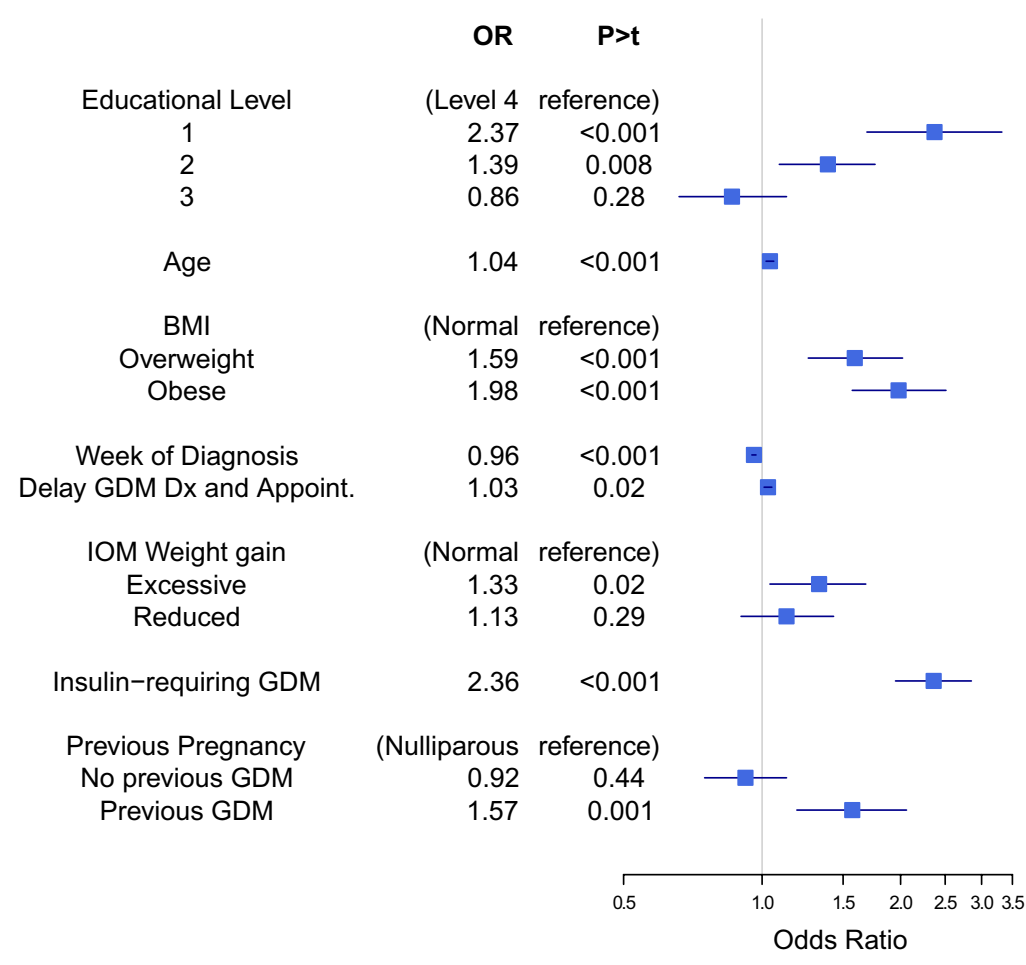

(b)

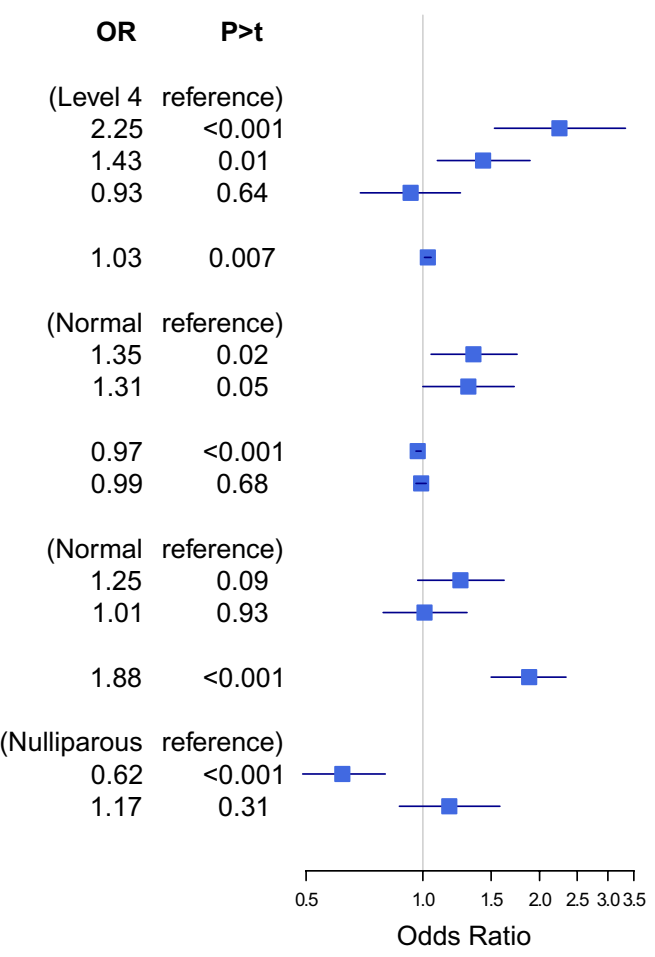

Fig. 1 Forest plots for a univariable and b multivariable logistic regression $(n=3978)$ indicating the association, effect size and direction between confounder variables and educational level and higher probability of persistent post-partum glucose metabolism disorders. Odds ratios (OR) with 95\% confidence intervals. Age in years, delay between GDM diagnosis ( $\mathrm{dx}$ ) and appointment in days 

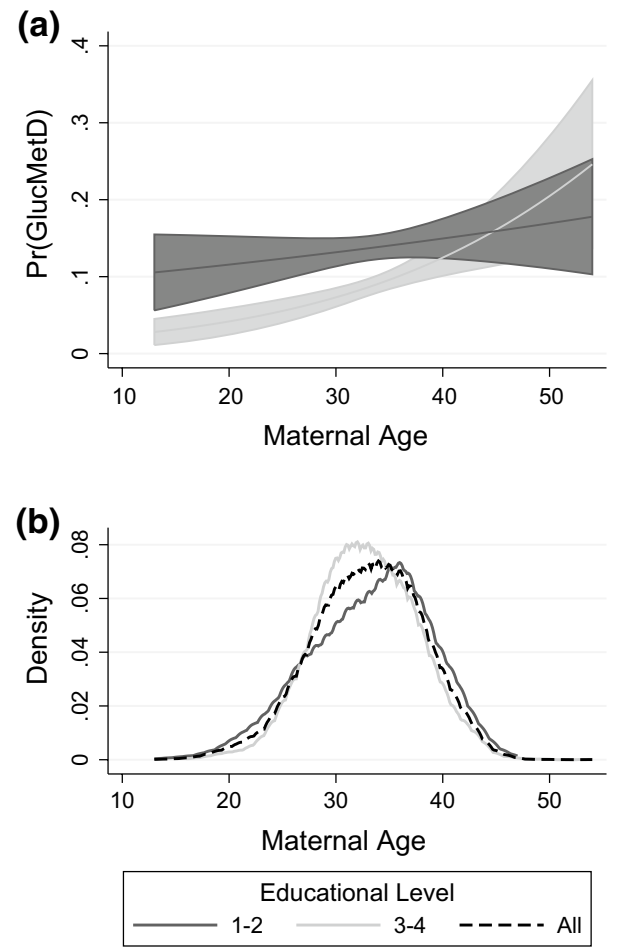

Fig. 2 a Margins plot with 95\% confidence intervals for effect modification by age of the educational level influence on the probability of persistent post-partum glucose metabolism disorders, b density plot for maternal age. Maternal age in years. Predicted probability of glucose metabolism disorders [Pr(GlucMetD)] having persistent post-partum glucose metabolism disorders increased with age to a lower degree in educational levels 1-2 than in levels 3-4 (Fig. 2a). Moreover, the difference between the groups was only significant before the maternal age of 37 years, encompassing the majority of the participants (Fig. 2b).

\section{Educational level influences glycemic control resulting in higher probability of requiring insulin during pregnancy}

Participants with educational levels 1 and 2 had a higher probability of needing insulin during pregnancy $(\mathrm{OR}=1.39$ $[1.03 ; 1.87], p=0.03$ and $\mathrm{OR}=1.39[1.16 ; 1.68], p=0.001$ for level 1 and 2, respectively, and when compared to level 4) (Fig. 3). It is also worth noticing that excessive weight gain $(\mathrm{OR}=1.21[1.01 ; 1.45], p=0.04)$, previous pregnancy with GDM $(\mathrm{OR}=1.48[1.18 ; 1.85], p=0.001$ compared to nulliparous), age $(\mathrm{OR}=1.02[1.01 ; 1.04], p=0.006)$ and higher pre-pregnancy BMI (OR $=1.53[1.29 ; 1.82], p<0.001$ for overweight and $\mathrm{OR}=2.20$ [1.84;2.63], $p<0.001$ for obese participants) were also associated with increased probability of insulin-requiring GDM.
Fig. 3 Forest plot for multivariable logistic regression indicating the association, effect size and direction between confounder variables and educational level and higher probability of insulin-requiring GDM pregnancy. Odds ratios (OR) with $95 \%$ confidence intervals. Age in years, delay between GDM diagnosis (dx) and appointment in days
Multivariable logistic regression $(n=3978)$

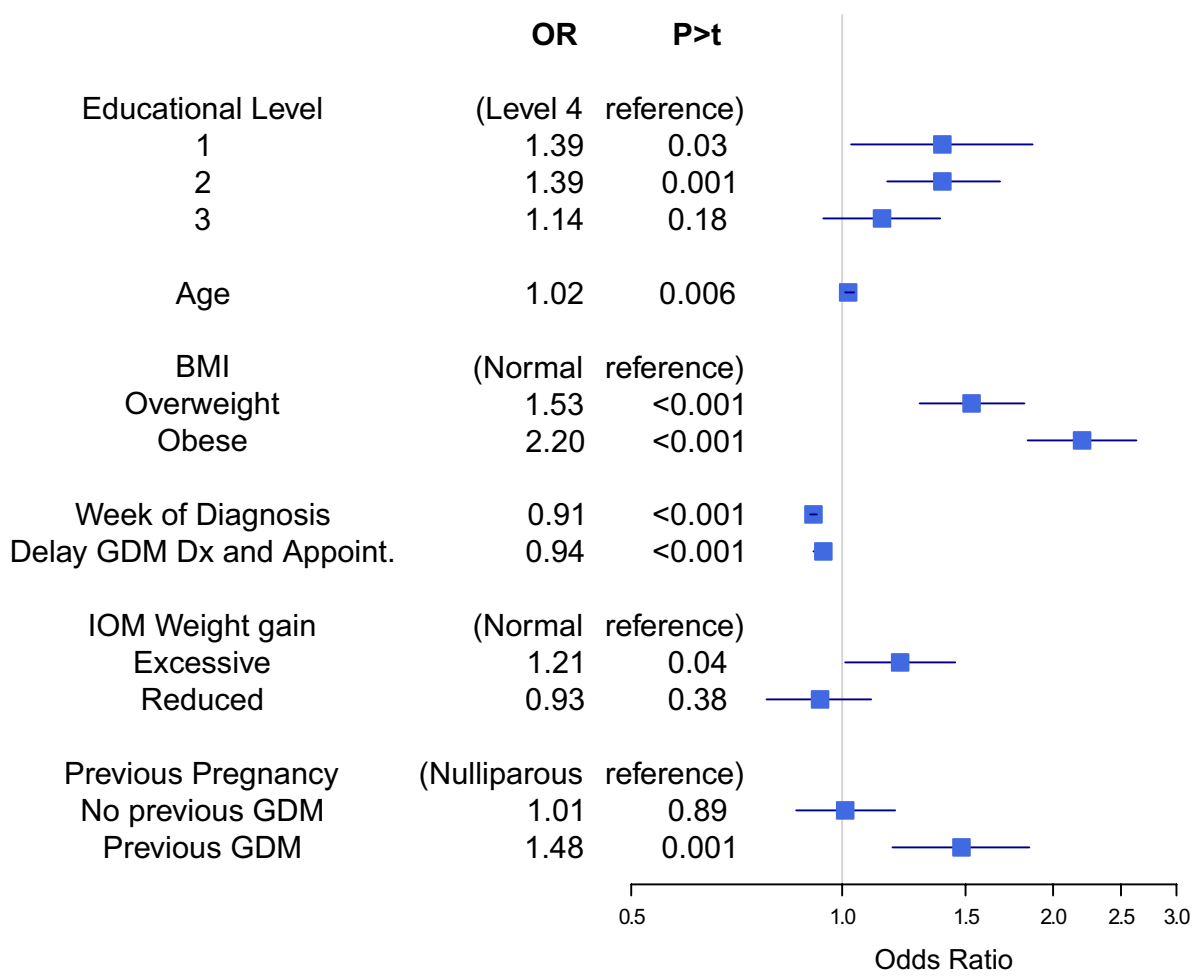




\section{Discussion}

We characterised a cohort of women with GDM, followed in more than half of all public sector health institutions in Portugal between the years 2008 and 2012, and we observed that persistent glucose metabolism disorders at 6 weeks post-partum are frequent $(10.9 \%)$ and associated with lower educational levels. While Bouthoorn et al. showed an association between this socio-economic indicator and GDM risk [14], an unequal persistence of post-partum glucose metabolism disorders in women with GDM has not, to the best of our knowledge, been previously described in such a large cohort and has potential public health implications.

We must acknowledge the limitations of our study. First, the observational nature of a cohort study design prevents us from inferring causality and the retrospective analysis, despite the large dataset, limits the study's conclusions. Second, different and evolving diagnostic criteria for GDM, as well as pre-diabetes stages are a concern, although a difficult one to overcome as they lack a universal definition. Third, the absence of baseline glycemic measures does not allow us to determine if lower educated women already had undiagnosed glucose metabolism disorders, other than type 2 DM, before pregnancy. Fourth, only 25 of the 44 public sector healthcare institutions managing gestational diabetes mellitus agreed to participate in this study, what may limit the generalisability of the study results. Fifth, missing data for outcome and explanatory variables were high, with missing data for the outcome $(36.5 \%)$ being in line with previous reports of non-adherence to gestational diabetes mellitus post-partum screening $[20,22]$. While we tried to address missing data by describing it and using multiple imputation, it is possible that our assumptions concerning their nature might not be accurate. Finally, during the years included in our study insulin was the mainstay of pharmacological treatment of GDM, as it preceded the widespread acceptance and generalisation of the use of metformin during pregnancy. It would be of interest to assess if our findings persist after the implementation of this new approach.

The results from our cohort agree with what has been described for this patient population [24-26]: older age, higher pre-pregnancy BMI, earlier week of diagnosis and requirement for pharmacological treatment were associated with persistent glucose metabolism disorders. Inversely, a previous pregnancy without GDM was associated with normal post-partum glucose metabolism.

The association between lower educational level and glucose metabolism disorders at 6 weeks post-partum was consistent throughout the years encompassed in this study and across different geographical areas. Lower educated women were older, had higher pre-pregnancy BMI at the first pregnancy visit, gained more weight during pregnancy and had a higher probability of insulin-requiring GDM during pregnancy compared to other educational strata. The association we identified could be partly due to these confounding factors, widely known to be potential causes for both type 2 DM and GDM. However, the fact that the association between educational level and the outcome was independent of said confounders suggests that other mechanisms concur towards this deleterious outcome. Lower educational levels may be associated with specific lifestyle habits, mainly lack of exercise and/or unhealthy diet, which are important risks factors for type $2 \mathrm{DM}$ and not measured in our cohort. It is plausible that women with lower educational level may be exposed to other socioeconomic factors, such as worse employment conditions, less free time to perform leisure activities and physical exercise.

Other potential unmeasured confounders could influence this association. A possible contributing factor could be worse glycemic control during pregnancy, but the lack of association between third trimester $\mathrm{HbA} 1 \mathrm{c}$ and educational level seems to contradict this hypothesis (data available in Table S4). However, the role of HbA1c as a marker of glycemic control during pregnancy has recently been challenged, as physiological changes (such as anaemia) and the short duration of altered glycemic control during pregnancy might preclude the use of this marker [27]. We also showed that lower maternal educational level was related to higher probability of insulin-requiring GDM, suggesting worse glycemic control in low educated participants that could result in the observed persistent post-partum glucose metabolism disorders. Nevertheless, the inclusion of this variable in the logistic regression model did not remove the significance of educational level in predicting the outcome, suggesting that worse glycemic control was not sufficient to explain the observed effect.

Type $2 \mathrm{DM}$ increasing prevalence is a major concern, making it a key target for public health interventions [28]. Impaired fasting glucose and impaired glucose tolerance are known to be pre-diabetic conditions associated with a higher risk of developing type $2 \mathrm{DM}$ later in life [11, 29]. As such, it is important to know which women with GDM are at the highest risk for persistent glucose metabolism disorders. This group could benefit from targeted interventions aimed at preventing persistent glucose metabolism disorders and/or effectively reducing the risk of progression to overt diabetes, as underscored in the 2015 ADA Diabetes Guidelines [30].

In conclusion, we believe information originating from this large cohort is valuable in both adding to current knowledge and suggesting future research paths. While this study was performed using a Portuguese population, educational level heterogeneity occurs universally and understanding 
how widespread the association with persistent post-partum glucose metabolism disorders actually is, would be of great importance. Future studies may enable the development of targeted public health interventions focused on reducing the observed inequities in post-partum glucose metabolism disorders in this population and, consequently, contribute to a reduction in the global burden of diabetes and its complications.

Acknowledgements We thank the multidisciplinary teams of obstetricians and diabetologists of Portuguese health institutions who collected patient data for the National Registry of Gestational Diabetes. In addition, we would like to acknowledge the alumni and faculty of the Harvard Medical School-Portugal Clinical Scholars Research Training Programme for useful scientific discussions. DP was partially supported by Fundação para a Ciência e Tecnologia under the Program for doctoral training in clinical research for medical interns (SFRH/ SINT/95317/2013).

Funding This research did not receive any specific grant from funding agencies in the public, commercial or not-for-profit sectors.

\section{Compliance with ethical standards}

Conflict of interest All authors declare that they have no conflict of interest.

Ethical approval All procedures in this study were in accordance with the ethical standards of the institutional and national research committee and with the 1964 Declaration of Helsinki and its later amendments or comparable ethical standards.

Informed consent For this type of study using retrospective and anonymised data, participants' written consent was not required.

\section{References}

1. Kampmann U, Madsen LR, Skajaa GO, Iversen DS, Moeller N, Ovesen P (2015) Gestational diabetes: a clinical update. World J Diabetes 6(8):1065-1072. https://doi.org/10.4239/wjd.v6.i8.1065

2. Metzger BE, Lowe LP, Dyer AR, Trimble ER, Chaovarindr U, Coustan DR et al (2008) Hyperglycemia and adverse pregnancy outcomes. N Engl J Med 358(19):1991-2002. https://doi. org/10.1056/NEJMoa0707943

3. Di Cianni G, Miccoli R, Volpe L, Lencioni C, Del Prato S (2003) Intermediate metabolism in normal pregnancy and in gestational diabetes. Diabetes Metab Res Rev 19(4):259-270. https://doi. org/10.1002/dmrr.390

4. Gorgal R, Goncalves E, Barros M, Namora G, Magalhaes A, Rodrigues $\mathrm{T}$ et al (2012) Gestational diabetes mellitus: a risk factor for non-elective cesarean section. J Obstet Gynaecol Res 38(1):154-159. https://doi.org/10.1111/j.1447-0756.2011.01659.x

5. Mitanchez D, Yzydorczyk C, Simeoni U (2015) What neonatal complications should the pediatrician be aware of in case of maternal gestational diabetes? World J Diabetes 6(5):734-743. https://doi.org/10.4239/wjd.v6.i5.734

6. Simeoni U, Barker DJ (2009) Offspring of diabetic pregnancy: long-term outcomes. Semin Fetal Neonatal Med 14(2):119-124. https://doi.org/10.1016/j.siny.2009.01.002
7. Yogev C, Hod C, Oats M et al (2010) Hyperglycemia and Adverse Pregnancy Outcome (HAPO) study: preeclampsia. Am J Obstet Gynecol 202(3):255 e1-255 e7. https://doi.org/10.1016/ j.ajog.2010.01.024

8. Kim C, Newton KM, Knopp RH (2002) Gestational diabetes and the incidence of type 2 diabetes: a systematic review. Diabetes Care 25(10):1862-1868

9. Expert Committee on the Diagnosis and Classification of Diabetes Mellitus (2003) Report of the expert committee on the diagnosis and classification of diabetes mellitus. Diabetes Care 26(Suppl 1):S5-S20. https://doi.org/10.2337/diacare.26.2007. S5

10. Grundy SM, Benjamin IJ, Burke GL, Chait A, Eckel RH, Howard BV et al (1999) Diabetes and cardiovascular disease: a statement for healthcare professionals from the American Heart Association. Circulation 100(10):1134-1146

11. Nathan DM, Davidson MB, DeFronzo RA, Heine RJ, Henry RR, Pratley R et al (2007) Impaired fasting glucose and impaired glucose tolerance: implications for care. Diabetes Care 30(3):753759. https://doi.org/10.2337/dc07-9920

12. Lee AJ, Hiscock RJ, Wein P, Walker SP, Permezel M (2007) Gestational diabetes mellitus: clinical predictors and long-term risk of developing type 2 diabetes: a retrospective cohort study using survival analysis. Diabetes Care 30(4):878-883. https://doi. org/10.2337/dc06-1816

13. Magliano DJ, Barr EL, Zimmet PZ, Cameron AJ, Dunstan DW, Colagiuri $S$ et al (2008) Glucose indices, health behaviors, and incidence of diabetes in Australia: the Australian Diabetes, Obesity and Lifestyle Study. Diabetes Care 31(2):267-272. https://doi. org/10.2337/dc07-0912

14. Bouthoorn SH, Silva LM, Murray SE, Steegers EA, Jaddoe VW, Moll H et al (2015) Low-educated women have an increased risk of gestational diabetes mellitus: the Generation R Study. Acta Diabetol 52(3):445-452. https://doi.org/10.1007/s00592-014-0668-x

15. Carpenter MW, Coustan DR (1982) Criteria for screening tests for gestational diabetes. Am J Obstet Gynecol 144(7):768-773

16. World Health Organization (2014) Diagnostic criteria and classification of hyperglycaemia first detected in pregnancy: a World Health Organization Guideline. Diabetes Res Clin Pract 103(3):341-363. https://doi.org/10.1016/j.diabres.2013.10.012

17. Metzger BE, Gabbe SG, Persson B, Buchanan TA, Catalano PA, Damm P et al (2010) International association of diabetes and pregnancy study groups recommendations on the diagnosis and classification of hyperglycemia in pregnancy. Diabetes Care 33(3):676-682. https://doi.org/10.2337/dc09-1848

18. Rasmussen KM, Yaktine AL (eds) (2009) Weight gain during pregnancy-reexamining the guidelines. Washington (DC): National Academies Press (US)

19. Dores JM, Magalhães A, Carvalheiro M (2017) Relatório de Consenso sobre a Diabetes e Gravidez. Portuguese General-Directorate of Health. 2011. http://www.saudereprodutiva.dgs.pt/ficheiro s-de-upload-diversos/relatorio-de-consenso-pdf.aspx

20. Ferrara A, Peng T, Kim C (2009) Trends in postpartum diabetes screening and subsequent diabetes and impaired fasting glucose among women with histories of gestational diabetes mellitus: a report from the Translating Research Into Action for Diabetes (TRIAD) Study. Diabetes Care 32(2):269-274. https://doi. org/10.2337/dc08-1184

21. Bennett WL, Ennen CS, Carrese JA, Hill-Briggs F, Levine DM, Nicholson WK et al (2011) Barriers to and facilitators of postpartum follow-up care in women with recent gestational diabetes mellitus: a qualitative study. J Womens Health (Larchmt) 20(2):239-245. https://doi.org/10.1089/jwh.2010.2233

22. Pastore I, Chiefari E, Vero R, Brunetti A (2017) Postpartum glucose intolerance: an updated overview. Endocrine. https://doi. org/10.1007/s12020-017-1388-0 
23. White IR, Royston P, Wood AM (2011) Multiple imputation using chained equations: issues and guidance for practice. Stat Med 30(4):377-399. https://doi.org/10.1002/sim.4067

24. Coustan DR, Carpenter MW, O'Sullivan PS, Carr SR (1993) Gestational diabetes: predictors of subsequent disordered glucose metabolism. Am J Obstet Gynecol 168(4):1139-1144 (discussion 44-5)

25. Kjos SL, Buchanan TA, Greenspoon JS, Montoro M, Bernstein GS, Mestman JH (1990) Gestational diabetes mellitus: the prevalence of glucose intolerance and diabetes mellitus in the first two months post partum. Am J Obstet Gynecol 163(1 Pt 1):93-98

26. Schaefer-Graf UM, Buchanan TA, Xiang AH, Peters RK, Kjos SL (2002) Clinical predictors for a high risk for the development of diabetes mellitus in the early puerperium in women with recent gestational diabetes mellitus. Am J Obstet Gynecol 186(4):751-756
27. Nielsen LR, Ekbom P, Damm P, Glumer C, Frandsen MM, Jensen $\mathrm{DM}$ et al (2004) HbA1c levels are significantly lower in early and late pregnancy. Diabetes Care 27(5):1200-1201

28. Wild S, Roglic G, Green A, Sicree R, King H (2004) Global prevalence of diabetes: estimates for the year 2000 and projections for 2030. Diabetes Care 27(5):1047-1053

29. Karve A, Hayward RA (2010) Prevalence, diagnosis, and treatment of impaired fasting glucose and impaired glucose tolerance in nondiabetic U.S. adults. Diabetes Care 33(11):2355-2359. https://doi.org/10.2337/dc09-1957

30. American Diabetes Association (2015) 5. Prevention or delay of type 2 diabetes. Diabetes Care 38(Suppl 1):S31-S32. https://doi. org/10.2337/dc15-S008

\section{Affiliations}

\section{Inês Gante ${ }^{1} \cdot$ Ana Carina Ferreira $^{2} \cdot$ Gonçalo Pestana $^{3} \cdot$ Daniela Pires $^{4,5} \cdot$ Njila Amaral $^{6}$. Jorge Dores ${ }^{7}$. Maria do Céu Almeida ${ }^{1}$. José Luis Sandoval ${ }^{8}$ (B)}

1 Department of Obstetrics, Maternidade Bissaya Barreto Centro Hospitalar e Universitário de Coimbra, Rua Augusta, 3000-061 Coimbra, Portugal

2 Department of Nephrology, Hospital Curry Cabral - Centro Hospitalar Lisboa Central, Rua Beneficência 8, 1069-166 Lisbon, Portugal

3 Department of Cardiology, Centro Hospitalar de São João, Alameda Prof. Hernâni Monteiro, 4200-319 Porto, Portugal

4 Department of Infectious Diseases, Centro Hospitalar de Lisboa Norte and Faculdade de Medicina de Lisboa, Av. Egas Moniz, 1649-035 Lisbon, Portugal
5 Infection Control Program, Geneva University Hospitals, Rue Gabrielle Perret-Gentil, 1205 Geneva, Switzerland

6 Department of Obstetrics and Gynecology, Hospital Beatriz Angelo, Avenida Carlos Teixeira 3, 2674-514 Loures, Portugal

7 Department of Endocrinology, Centro Hospitalar do Porto, Largo Prof. Abel Salazar, 4099-001 Porto, Portugal

8 Unit of Population Epidemiology, Department of Community Medicine, Primary Care, and Emergency Medicine, Geneva University Hospitals, Rue Gabrielle Perret-Gentil, 1205 Geneva, Switzerland 